Abanico Agroforestal. Enero-Diciembre 2020; 2:1-13. http://dx.doi.org/10.37114/abaagrof/2020.5 Artículo Original. Recibido: 06/12/2019. Aceptado: 15/04/2020. Publicado: 25/04/2020.

\title{
Inducción in vitro de callogénesis y organogénesis en explantes de Krameria erecta Willd
}

In vitro induction of callogenesis and organogenesis in explants of Krameria erecta Willd

\section{Mc-Caughey-Espinoza Diana ${ }^{* 1} \stackrel{\mathbb{I}}{ }$, Reyes-Olivas Álvaro ${ }^{1} \stackrel{\mathbb{D}}{ }$, Ayala-Astorga Gloria ${ }^{2} \underline{\text { ID }}$, Lugo-García Gabriel ${ }^{1} \stackrel{\mathrm{ID}}{ }$, Ochoa-Meza Andrés 3 ID, Pacheco-Olvera Antonio ${ }^{4} \underline{\mathrm{ID}}$}

${ }^{1}$ Colegio de Ciencias Agropecuarias, Facultad de Agricultura del Valle del Fuerte, Universidad Autónoma de Sinaloa. México. ${ }^{2}$ Departamento de Investigaciones Científicas y Tecnológicas de la Universidad de

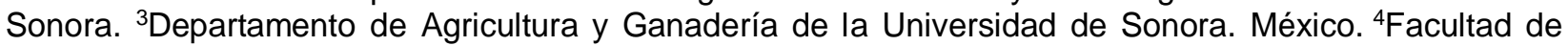
Agronomía de la Universidad Autónoma de Sinaloa. México. diana.mccaughey@unison.mx, alreo.uas@gmail.com, gloria.ayala@unison.mx, andres.ochoa@unison.mx y apontoniopo345@gmail.com

gabriel_lugo9010@hotmail.com,

\section{RESUMEN}

El objetivo de la presente investigación fue evaluar in vitro la germinacion e inducción de callogenesis y organogénesis en explantes de Krameria erecta. El medio de cultivo utilizado fue WPM/50 a la mitad de sales y conformado de vitaminas, sacarosa y ácido indolbutirico (IAB), en concentraciones $(0,0.5,1.0,1.5$ y $2 \mathrm{mgL}^{1}$ ). Los explantes fueron incubados en ambiente controlado de $25^{\circ} \mathrm{C}$ y foto periodo de 16 horas luz. El diseño experimental fue completamente aleatorizado con un arreglo factorial de $5 \times 3$ con un ANDEVA $(P<0.05)$ y la prueba de media de Tukey. La germinación in vitro no presento diferencias significativas mostrando de un 79 a $83 \%$. Se presentaron diferencias significativas en altura de plántulas, las concentraciones de 1.5 y $2.0 \mathrm{mgL}^{1}$ de AIB fueron superiores con 11.60 a $11.65 \mathrm{~cm}$. La altura y ancho de callo en yema axilar y hoja se presentaron diferencias significativas en concentraciones de 1.0 y $2 \mathrm{mgL}^{1}$ de AIB. En lo que respecta al número de raíz en hoja fue de 0.50 a 2.50, mostrándose diferencias significativas en las concentraciones, en yema axilar no se presentó raíz por lo tanto no se presentaron diferencias significativas. En contaminación no se presentaron diferencias significativas presentado abajo del 12.50\%. de acuerdo la desinfección con alcohol e hipoclorito de sodio $(\mathrm{NaClO})$ no se presentó oxidación en semillas, pero si en yema axilar y hojas.

Palabras clave: cultivo de tejido, ácido indolbutirico, explantes y Krameria erecta

\begin{abstract}
The objective of the present investigation was to evaluate in vitro the germination and induction of callogenesis and organogenesis in explants of Krameria erecta. The culture medium used was WPM / 50 with half the salts and made up of vitamins, sucrose and indolebutyric acid (IAB), in concentrations (0, 0.5, 1.0, 1.5 and $2 \mathrm{mgL}^{1}$ ). The explants were incubated in a controlled environment of $25^{\circ} \mathrm{C}$ and photo period of 16 light hours. The experimental design was completely randomized with a $5 \times 3$ factorial arrangement with an ANDEVA $(P<0.05)$ and the Tukey mean test. In vitro germination did not present significant differences, showing from 79 to $83 \%$. There were significant differences in seedling height, the concentrations of 1.5 and $2.0 \mathrm{mgL}^{1}$ of AIB were higher with 11.60 to $11.65 \mathrm{~cm}$. The height and width of callus in axillary bud and leaf presented significant differences in concentrations of 1.0 and $2 \mathrm{mgL}^{1}$ of AIB. Regarding the number of root in the leaf it was from 0.50 to 2.50 , showing significant differences in the concentrations, in the axillary bud there was no root, therefore there were no significant differences. In contamination, there were no significant differences presented below $12.50 \%$. According to the disinfection with alcohol and sodium hypochlorite $(\mathrm{NaClO})$, there was no oxidation in seeds, but in axillary bud and leaves.
\end{abstract}

Keywords: tissue culture, indolebutyric acid, explants and Krameria erecta. 


\section{INTRODUCCION}

La familia de las Krameriaceae comprende 17 especies en un solo género Krameria erecta W. (Dominguez et al., 1987; Simpson et al., 2004); se distribuye geográficamente al norte de México, principalmente en Sonora, Sinaloa, Chihuahua, Durango, Coahuila, Baja California, Zacatecas y en los estados de California, Utah y Nevada en Estados Unidos de América (Simpson and Salywon, 1999).

Es un arbusto forrajero con importancia económica en las zonas áridas y semi-áridas del noroeste de México (Mc-Caughey-Espinoza et al., 2019). Su importancia en el campo de la medicina se debe a que presenta alta actividad antiproliferativa en células cancerígenas y un alto contenido de flavonoides; además, tiene efectos hepatoprotector, antioxidante y antiinflamatorio, y posee cinto veces más actividad antioxidante que el ácido ascórbico (Carini et al., 2002; Jiménez-Estrada et al., 2013; Morán-Palacio et al., 2014). Cabe mencionar que a esta planta se le extrae la tintura de la raíz, la cual es utilizada por los Seris, etnia importante del estado de Sonora.

En los últimos 20 años los trabajos de propagación in vitro de algunas especies forestales se han incrementado paulatinamente; no obstante, hasta el momento no se han realizado trabajos que reporten la micropropagación in vitro de krameria erecta Willd.

La distribución de $K$. erecta se encuentra limitada en los ecosistemas naturales, por factores como: sobre pastoreo, cambio de uso de suelo, bajas precipitaciones, presencia de insectos, etc. En su hábitad natural se pueden encontrar de cero hasta 70 plantas en 2500 metros cuadrados, la presencia de nuevos individuos prácticamente es inexistente. Con la aplicación de la biotecnología se pueden conservar los ecosistemas naturales aún presentes en nuestro entorno. Una de las estrategias utilizadas para contrarrestar los problemas presentes en la propagación de las especies forestales y la extinción de estas, es el cultivo in vitro de cultivo vegetal (Delgado et al., 2008).

Para aminorar la situación de las bajas poblaciones que existen en los agostaderos del estado de Sonora, y por ser una planta apetecible por los animales herbívoros y medicinal; el propósito de esta investigación es establecer una metodología para la germinación e inducción de callogénesis y organogénesis in vitro en yemas axilares y hoja de krameria erecta W.

\section{MATERIAL Y MÉTODOS}

La región de recolecta de Krameria erecta Willd se realizó entre las coordenadas $29^{\circ} 03^{\prime} 21.30^{\prime \prime}$ de Latitud Norte y los $110^{\circ} 45^{\prime} 12.22$ " de Longitud Oeste (rancho Las Cruces). Durante el mes de septiembre del 2019, las partes útiles de la planta, fueron los explantes de tallo, hoja y semillas; generalmente sólo el $20 \%$ pueden ser semillas fisiológicamente maduras y viables. El material utilizado fue tijeras, bolsas ziplot e hielera. La investigación se realizó en el laboratorio de Biotecnología del Programa Educativo de Ingeniero en Horticultura de la Universidad Estatal de Sonora (UES). 


\section{Medio de cultivo}

El medio de cultivo utilizado fue Woody Plant Medium (WPM/50) (Trigiano and Gray, 2011); este medio se utilizó a la mitad de su concentración, constituido principalmente de sales minerales y vitaminas, tales como: tiamina, mio-inositol, sacarosa y agar. La fitohormona que se utilizó fue: ácido indolbutírico, a concentraciones de 0, 0.5, 1.0,1.5 y $2.0 \mathrm{mgL}^{-1}$. No se aplicó antioxidantes al medio.

\section{Cámara de flujo laminar}

La cámara de flujo laminar (Marca Edge Gard Hood), se desinfectó previamente antes de realizar los cultivos, utilizando alcohol al 99\% y vickor, y posteriormente durante 30 min se dejó encendida una lámpara de luz fluorescente de $40 \mathrm{~W}$, la cual proporcionó una irradiación de 8-10 W. $\mathrm{m}^{2}{ }^{2}$. Se utilizaron tubos de ensayo y frascos tipo gérber de vidrio transparente. También se utilizaron cajas Petri de vidrio, pinzas y bisturí; todo el material fue previamente esterilizado en una autoclave modelo Sterilmatic, a una temperatura de $120^{\circ} \mathrm{C}$ y $15 \mathrm{~kg} / \mathrm{cm}^{2}$ de presión durante 15 minutos.

\section{Cultivo de explantes}

Las semillas fueron previamente embebidas con agua desionizada, durante 2 horas antes de la siembra. Los explantes (hojas tallos, yemas axilares, apicales y semillas sin pericarpio, fueron embebidas durante 3 horas en agua desionizada), después se desinfectaron con alcohol etílico al $70 \%$ durante 3 minutos; y posteriormente en hipoclorito de sodio $(\mathrm{NaClO})(\mathrm{CLOROX} \circledast)$ ) al 15\% durante $12 \mathrm{~min}$, añadiendo una gota de tween 20; se realizaron 3 enjuagues con agua desionizada. Posteriormente se colocaron en una solución antioxidante de ácido ascórbico (150 mg/L) y ácido cítrico (100 mg/L) durante 5 minutos, y posteriormente se sembraron.

\section{Incubación}

Para la siembra se utilizaron frascos de vidrio tipo gérber. Los explantes fueron previamente sembrados; posteriormente se colocaron el cuarto de incubación, en condiciones controladas, manteniendo una temperatura de $25 \pm 1^{\circ} \mathrm{C}$, y un fotoperiodo de 16 horas luz con 8 horas de oscuridad y $70-75 \%$ de humedad relativa.

\section{Parámetros evaluados}

La evaluación se realizó por observación y medición en los diferentes explantes, iniciándose al tercer día de su incubación y posteriormente se observaron y se realizaron mediciones cada siete días durante 2 meses.

Los parámetros evaluados fueron:

- Porciento de germinacion (\%), utilizándose el criterio de la ISTA (2019).

- Mediciones de callos presentes en los explantes; se utilizó un vernier marca Mitutoyo Absolute Modelo CD-6CSX Nº de Serie 06401649 de 6" 
- Altura de plántulas $(\mathrm{cm})$

- Ancho y alto de callo (mm)

- Número de raíces

- Contaminación y oxidación

\section{Análisis estadístico}

El diseño experimental que se utilizó en este trabajo de investigación fue completamente aleatorizado, con un arreglo factorial de $5 \times 3$ (5 concentraciones y 3 explantes), con 10 repeticiones. Se realizó un análisis de varianza (ANDEVA), con un nivel de significancia de $\mathrm{P}<0.05$, y una comparación de medias de Tukey. Para el análisis de los datos se empleó el paquete estadístico JMP, versión 9.0.1 (Statistical Analysis System, [SAS Institute Inc.], 2011).

\section{RESULTADOS Y DISCUSIÓN}

\section{Germinación de las semillas in vitro}

La germinación in vitro inició el $4^{\text {to }}$ y concluyo al $15^{\text {to }}$ día. No se presentaron diferencias significativas en el porcentaje de germinación, entre tratamientos de AIB utilizadas en este estudio, presentado un porcentaje de germinación 79.0 a $83.0 \%$; estos resultados nos indican que para la germinación de la semilla de Krameria erecta no se requiere el uso de ningún tipo de fitohormona, en el medio de cultivo; al no ser significativo su porcentaje de germinación, ver tabla 1 y figura 1.

Con respecto al porcentaje de plántulas normales germinadas, se presentó diferencias significativas $(P \leq 0.05)$, entre las concentraciones de $\operatorname{AIB}\left(0.5,1.0,1.5\right.$ y $\left.2 \mathrm{mgL}^{-1}\right)$, con respecto al control (sin fitohormona); presentándose para el control un $71.25 \%$ de plántulas normales, y entre un 31.25 a $32.0 \%$ con el uso de AIB, ver tabla 1. Cabe mencionar que también se observaron diferencias significativas $(P \leq 0.05)$, al evaluar el porcentaje de plántulas anormales de krameria erecta, con respecto a los tratamientos, presentando de un $11.5 \%$ de plántulas anormales en el control; mientras que en los tratamientos con AIB se presentaron de 49.75 a $51.0 \%$ de plántulas anormales.

Tabla 1. Germinación in vitro y altura de plántulas de krameria erecta Willd.

\begin{tabular}{cccccc}
\hline $\begin{array}{c}\text { Tratamiento } \\
\text { AIB mgL }\end{array}$ & $\begin{array}{c}\text { Semillas germinadas } \\
(\%)\end{array}$ & $\begin{array}{c}\text { Plántulas } \\
\text { Normales (\%) }\end{array}$ & $\begin{array}{c}\text { Plántulas } \\
\text { anormales (\%) }\end{array}$ & $\begin{array}{c}\text { No germinadas } \\
(\%)\end{array}$ & $\begin{array}{c}\text { Plántulas } \\
\text { Altura (cm) }\end{array}$ \\
\hline 0 & $82.75 \pm 1.49^{\mathrm{a}}$ & $71.25 \pm^{\mathrm{a}}$ & $11.50 \pm 1.29^{\mathrm{b}}$ & $8.50 \pm 1.00^{\mathrm{a}}$ & $10.07 \pm 0.21^{\mathrm{b}}$ \\
0.5 & $81.50 \pm 1.49^{\mathrm{a}}$ & $31.25 \pm^{\mathrm{b}}$ & $50.25 \pm 2.75^{\mathrm{a}}$ & $9.75 \pm 0.50^{\mathrm{a}}$ & $10.42 \pm 0.21^{\mathrm{b}}$ \\
1.0 & $83.00 \pm 1.49^{\mathrm{a}}$ & $32.00 \pm^{\mathrm{b}}$ & $51.00 \pm 2.44^{\mathrm{a}}$ & $9.75 \pm 0.95^{\mathrm{a}}$ & $10.52 \pm 0.21^{\mathrm{b}}$ \\
1.5 & $79.00 \pm 1.49^{\mathrm{a}}$ & $31.75 \pm^{\mathrm{b}}$ & $49.75 \pm 2.50^{\mathrm{a}}$ & $10.50 \pm 1.29^{\mathrm{a}}$ & $11.65 \pm 0.21^{\mathrm{a}}$ \\
2.0 & $82.00 \pm 1.49^{\mathrm{a}}$ & $31.50 \pm^{\mathrm{b}}$ & $50.50 \pm 3.10^{\mathrm{a}}$ & $10.25 \pm 0.95^{\mathrm{a}}$ & $11.60 \pm 0.21^{\mathrm{a}}$
\end{tabular}

Medias con letras iguales dentro de la misma columna indican que no hay diferencias significativas $(\mathrm{P}<0.05)$. Los datos presentados son la media de 10 repeticiones con 3 muestras cada frasco por tratamiento. 
Al analizar el porcentaje de semillas no germinadas, no se presentaron diferencias significativas entre los tratamientos presentándose de 8.5 a $10.5 \%$ de semillas que no germinaron, ver tabla 1. Dichos resultados muestran que el uso de auxinas estimuló en la germinacion geotropismo negativo, al presentarse arriba del $50 \%$ de plántulas anormales.

Golubov et al., (2007), menciona que la germinación está ligada al crecimiento del embrión. La germinacion de plántulas normales fue menor del $32.00 \%$, al presentarse una radícula bien definida y la brotación de sus hojas seminales. De acuerdo a la AOSA (2005), indica que las plántulas que presentaron un crecimiento anormal no se desarrollan, al presentar deficiencias en su sistema radicular (falta de radícula, fototropismo negativo $u$ otras malformaciones).

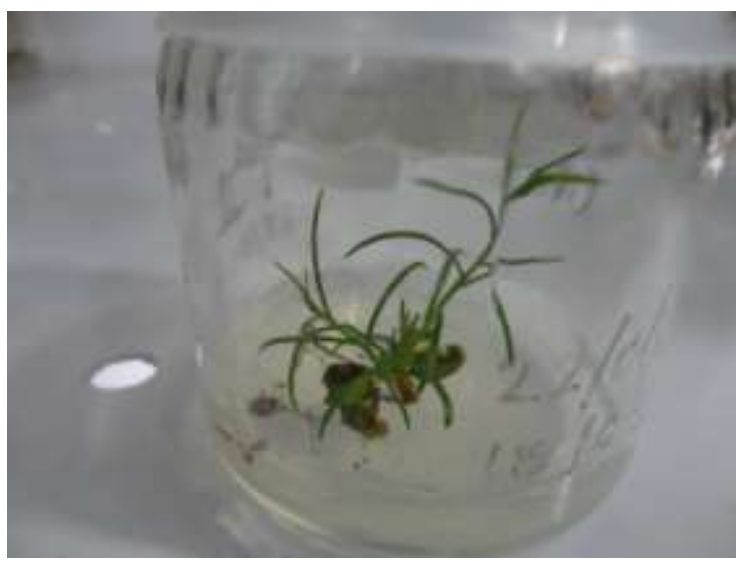

Figura 1. Germinacion in vitro de Krameria erecta

El porcentaje de germinación en Krameria erecta fue similar a los obtenidos por Golubov et al., (2007), obtuvieron porcentajes de germinación in vitro mayores al $80 \%$ en semillas de $B$. recurvata, que fueron almacenadas (en deshidratación con sílica gel), durante seis años, a $6^{\circ} \mathrm{C}$, con humedad relativa baja.

\section{Altura de plántulas}

La altura de las plántulas de krameria erecta, presentaron diferencias significativas $(P \leq 0.05)$ entre los tratamientos evaluados, ver tabla 1. Las plántulas con los tratamientos de 1.5 a $2.0 \mathrm{mgL}^{-1}$ de AIB presentaron 11.60 a $11.66 \mathrm{~cm}$ de altura, sin tener entre estas diferencias significativas; mientras que $0,0.5$ y $1.0 \mathrm{mgL}^{-1}$ de AIB, no presentaron diferencias significativas, mostrando 10.07 a $10.52 \mathrm{~cm}$. Las plántulas presentaron características propias y morfológicamente similares a las plantas presentes en su hábitad silvestre.

\section{Inducción de callo y raíz}

De acuerdo a los explantes utilizados en esta investigación, se mostró que existen diferencias significativas $(P \leq 0.05)$ con respecto a la altura de los callos, de 0.58 a 0.67 
$\mathrm{mm}$ de alto, ver tabla 2 y figura 2; excepto el tratamiento de cero $\mathrm{mgL}^{-1}$ de AIB (control), no presentó callo. En lo que respecta a lo ancho del callo, también se presentaron diferencias significativas $(P \leq 0.05)$, de acuerdo al análisis estadístico, indicando de 0.76 a $0.96 \mathrm{~mm}$ en los tratamientos de $0.5,1.0,1.5$ y $2.0 \mathrm{mgL}^{-1}$ de AIB.

En yema axilar se presentaron diferencias significativas $(P \leq 0.05)$ entre los tratamientos, excepto en 1.5 y $2.0 \mathrm{mgL}^{-1}$ de AIB; presentando alturas en yemas de 0.93 a $0.96 \mathrm{~mm}$. En lo que respecta a lo ancho del callo en yema axilar, se presentaron diferencias significativas $(P \leq 0.05)$ entre los tratamientos de $1.0,1.5$ y $2.0 \mathrm{mgL}^{-1}$ de $\mathrm{AlB}$, con respecto a 0.5 y $0 \mathrm{mgL}^{-1}$ de AIB. El tratamiento de cero $\mathrm{mgL}^{-1}$ de AIB (control) no presentó callo, ver tabla 2. A pesar de la diferencia significativa que existen entre los tratamientos, cabe mencionar que la aplicación de auxina (AIB) es eficaz para la inducción de callo en hoja y en yema axilar de cosahui del sur (Krameria erecta), presentado un color inicial blanco y tornarse a verde claro, con una consistencia firme; por lo tanto, podemos señalar que los callos son viables para la inducción de ser un callo embriogénico.

Tabla 2. Inducción de callo y raíz en explantes de krameria erecta Willd

\begin{tabular}{clccccc}
\hline $\begin{array}{c}\text { Tratamiento } \\
\text { AlB mgL }\end{array}$ & \multicolumn{2}{c}{ Altura callo $(\mathrm{mm})$} & \multicolumn{2}{c}{ Ancho callo $(\mathrm{mm})$} & \multicolumn{2}{c}{ Numero de raíz } \\
\cline { 2 - 7 } & Hoja & Yema axilar & Hoja & Yema axilar & Hoja & Yema axilar \\
\hline 0 & $0.00 \pm 0.00^{\mathrm{d}}$ & $0.00 \pm 0.00^{\mathrm{c}}$ & $0.00 \pm 0.00^{\mathrm{d}}$ & $0.00 \pm 0.00^{\mathrm{c}}$ & $0.00 \pm 0.00^{\mathrm{c}}$ & $0.00 \pm 0.00^{\mathrm{a}}$ \\
0.5 & $0.58 \pm 0.00^{\mathrm{c}}$ & $0.45 \pm 0.00^{\mathrm{b}}$ & $0.76 \pm 0.01^{\mathrm{c}}$ & $0.56 \pm 0.01^{\mathrm{b}}$ & $0.50 \pm 0.57^{\mathrm{b}}$ & $0.00 \pm 0.00^{\mathrm{a}}$ \\
1.0 & $0.65 \pm 0.01^{\mathrm{b}}$ & $0.46 \pm 0.00^{\mathrm{a}}$ & $0.86 \pm 0.02^{\mathrm{b}}$ & $0.58 \pm 0.00^{\mathrm{a}}$ & $1.25 \pm 0.95^{\mathrm{b}}$ & $0.00 \pm 0.00^{\mathrm{a}}$ \\
1.5 & $0.67 \pm 0.00^{\mathrm{a}}$ & $0.47 \pm 0.00^{\mathrm{a}}$ & $0.96 \pm 0.03^{\mathrm{a}}$ & $0.59 \pm 0.00^{\mathrm{a}}$ & $2.50 \pm 0.57^{\mathrm{a}}$ & $0.00 \pm 0.00^{\mathrm{a}}$ \\
2.0 & $0.67 \pm 0.00^{\mathrm{a}}$ & $0.47 \pm 0.00^{\mathrm{a}}$ & $0.93 \pm 0.03^{\mathrm{a}}$ & $0.59 \pm 0.00^{\mathrm{a}}$ & $2.00 \pm 0.81^{\mathrm{a}}$ & $0.00 \pm 0.00^{\mathrm{a}}$
\end{tabular}

Medias con letras iguales dentro de la misma columna indican que no hay diferencias significativas $(\mathrm{P}<0.05)$. Los datos presentados son la media de 10 repeticiones con 3 muestras cada frasco por tratamiento.

El porcentaje con relación a la presencia de callo en los explantes, en las hojas se presentaron hasta un $80 \%$; mientras que en el control presentó $0 \%$. El crecimiento de los callos se presentó a los 30 días de la incubación y su proliferación a las cuatro semanas de incubación. El porcentaje presente de callos en yemas axilares fue hasta un $60 \%$, excepto el control que no presentó. La inducción de callo en yemas axilares se presentó a las 6 semanas de incubación.

Los resultados indican que la mejor respuesta de inducción de callos en hojas o en yemas axilares se presentó al aplicar la concentración de 1.0 a 2.0. Es importante señalar que el explante ideal para la producción de callo fueron las hojas, de acuerdo al análisis estadístico aplicado. 


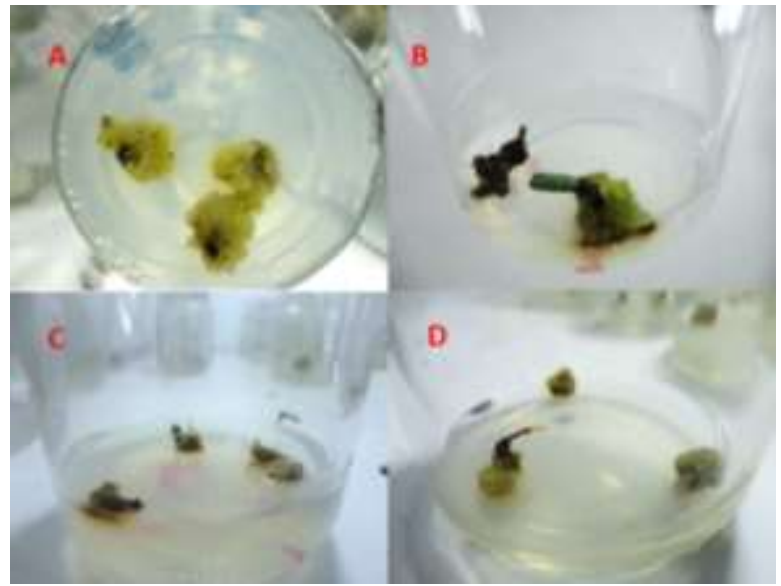

Figura 2- A: inducción de callo en hojas, B: inducción de callo en yema axilar, $C$ : raíz en hoja y $D$ : callo y raíz en hoja

Para el crecimiento celular las auxinas deben provocar dicha inducción de acuerdo a los genes que codifican los factores proteicos (Córdova et al., 2014); de esta manera las células se dilatan por la presión del agua en el interior de la vacuola, para seguir creciendo hasta que exista una resistencia de la pared celular (Azcón-Bieto y Talón 2008).

De acuerdo a Smith y Atkins (2002); Arellano et al., (2008), la inducción de callo se presenta al momento que las células crecen y almacenan nutrientes, y con la presencia de auxinas y las citosinas provocan que se acumulen y estimulan las ciclinas a nivel transcripcional, desencadenando la activación de las quinasas; y asimismo promover el nuevo ciclo celular y formación de callo. La inducción de callo es independiente del tipo de explante y fitohormona utilizada (Howell et al., 2003; Shiram et al., 2008; Rodríguez et al., 2014).

En este estudio se logró produccion de callogénesis con el uso de auxinas en yemas axilares y hojas de krameria erecta; por lo tanto, existe una estimulación en la mitosis, promoviendo la formación de tejido calloso (Smith 2012).

En cuanto al número de raíz presente en las hojas, se observaron diferencias significativas entre los tratamientos, mostrando raíces en las connotaciones de 0.5, 1.0, 1.5 y $2.0 \mathrm{mgL}^{-1}$ de AIB, excepto en el tratamiento cero $\mathrm{mgL}^{-1}$ de AIB (control), quien tuvo nula inducción de raíz. Mientras que en yema axilar no se presentaron diferencias significativas entre los tratamientos $\left(0,0.5,1.0,1.5\right.$ y $2.0 \mathrm{mgL}^{-1}$ de AIB), al no presentarse raíces, ver tabla 2 . El porcentaje de raíz presente en hoja fue del $30 \%$, mostrándose en hojas con presencia de callo.

Hasta hoy en día no existen trabajos referentes a este arbusto u otros arbustos, por lo tanto, se complica la discusión de la información por la escasa información que se recopiló; más sin embargo, se cuenta con otros estudios de otras especies y géneros diferentes, como Oryza sativa (Pérez et al., 2009) y Eucalyptus globulus (Gómez et al., 2006), etc. Con el método de cultivo in vitro, es posible obtener plantas de calidad uniforme, de acuerdo a un genotipo seleccionado (Levitus et al., 2010). Las fitohormonas 
no son especializadas para inducir mutaciones, ya que en concentraciones altas acelera los procesos de división celular, y posiblemente genere variaciones genéticas (George et al., 2008).

\section{Contaminación}

Los explantes, por su procedencia (área silvestre) traen algunos fitopatógenos, los cuales pueden causar problemas al momento de su siembra y desarrollarse para su proliferación. La contaminación se presentó básicamente en todas las concentraciones y explantes utilizados. Se presentaron bacterias y hongos ambientales (bióticos y abióticos), indicándose esta contaminación a partir del tercer día de incubación. Al analizar el porciento de contaminación presente en las semillas de Krameria erecta, de acuerdo a la concentración y tiempo de remojo que se manejó en esta investigación, no se presentaron diferencias significativas entre los tratamientos evaluados, al presentarse una tasa de contaminación de 7.25 a $8.75 \%$.

Es importante señalar que las plántulas desarrolladas in vitro estuvieron libres de contaminación por más de 3 meses; por lo tanto, el método de desinfección en semillas de Krameria erecta fue adecuado. Tampoco se presentaron diferencias significativas en cuando a la contaminación presente en los explantes de yema axilar y hoja, mostrando de 11.25 a $12.50 \%$ de contaminación, ver tabla 3 . Podemos señalar que fue efectivo el tratamiento de desinfección de los explantes, al utilizar etanol al $70 \%$ por 3 minutos, y posteriormente por 12 minutos en hipoclorito de sodio comercial al 15\%. La muerte de microorganismos es debido a la combinación del hipoclorito de sodio con las proteínas de las membranas celulares y las enzimas (Flores et al., 2008).

Tabla 3.-Contaminación y oxidación en explantes de krameria erecta Willd.

\begin{tabular}{|c|c|c|c|c|c|c|}
\hline \multirow{2}{*}{$\begin{array}{c}\text { Tratamiento } \\
\text { AlB } \mathrm{mgL}^{-1}\end{array}$} & \multicolumn{3}{|c|}{ Contaminación (\%) } & \multicolumn{3}{|c|}{ Oxidación (\%) } \\
\hline & Semillas & Hojas & Yema apical & Semillas & Hoja & Yema apical \\
\hline 0 & $8.75 \pm 1.08^{a}$ & $11.25 \pm 2.50^{\mathrm{a}}$ & $11.25 \pm 2.50^{\mathrm{a}}$ & $0.00 \pm 0.00^{\mathrm{a}}$ & $28.7 \pm 2.5^{\mathrm{a}}$ & $26.2 \pm 7.50^{\mathrm{a}}$ \\
\hline 0.5 & $8.75 \pm 1.08^{a}$ & $12.50 \pm 2.88^{a}$ & $12.50 \pm 2.88^{a}$ & $0.00 \pm 0.00^{a}$ & $28.7 \pm 4.7^{a}$ & $30.0 \pm 7.07^{a}$ \\
\hline 1.0 & $7.25 \pm 1.08^{a}$ & $11.25 \pm 2.50^{\mathrm{a}}$ & $11.25 \pm 2.50^{\mathrm{a}}$ & $0.00 \pm 0.00^{\mathrm{a}}$ & $28.7 \pm 2.5^{\mathrm{a}}$ & $26.2 \pm 7.50^{\mathrm{a}}$ \\
\hline 1.5 & $8.00 \pm 1.08^{a}$ & $11.25 \pm 2.50^{\mathrm{a}}$ & $12.50 \pm 2.88^{a}$ & $0.00 \pm 0.00^{\mathrm{a}}$ & $30.0 \pm 4.0^{a}$ & $26.2 \pm 7.50^{\mathrm{a}}$ \\
\hline 2.0 & $7.75 \pm 1.08^{a}$ & $11.25 \pm 2.50^{\mathrm{a}}$ & $12.50 \pm 2.88^{a}$ & $0.00 \pm 0.00^{a}$ & $28.7 \pm 2.5^{\mathrm{a}}$ & $26.2 \pm 7.50^{\mathrm{a}}$ \\
\hline
\end{tabular}

Medias con letras iguales dentro de la misma columna indican que no hay diferencias significativas $(\mathrm{P}<0.05)$. Los datos presentados son la media de 10 repeticiones con 3 muestras cada frasco por tratamiento.

La etapa fisiológica del tejido vegetal tiene gran influencia en el proceso de desinfección. El material de plantas en crecimiento se desinfecta más fácil que el de plantas maduras; sus depósitos de ceras y ligninas son mayores y son una barrera para la acción del agente desinfectante sobre los microorganismos endógenos (López et al., 2010; Pedroza et al., 
2007). Entre los contaminantes más comunes in vitro son las bacterias, éstas son difíciles de detectar y originan serios problemas (Orlikowska et al., 2017). Muchos microorganismos necesitan un tiempo de adaptación a las nuevas condiciones, previamente al manifestar su presencia, esto ocurre generalmente en la fase de multiplicación (Hernández y González, 2010).

\section{Oxidación}

En lo que respecta a la tasa de oxidación (oscurecimiento), en los explantes de manera general, no se presentaron diferencias significativas al analizar esta variable en los diferentes explantes (yema axilar y hoja), mostrando en hojas un 28.7 a $30.0 \%$ de oxidación; mientras que en yema axilar se presentó un 26.2 a 30.0\%. En lo que respecta a las semillas, éstas no presentaron oxidación, ver tabla 3. De acuerdo al bajo porcentaje de oxidación presente, se puede atribuir a la mezcla de antioxidantes utilizados (ácido ascórbico + ácido cítrico). En este trabajo se obtuvieron resultados favorables.

De acuerdo a Vatanpour-Azghandi et al., (2002); Tang y Newton, (2004); Gratão et al., (2005); Pompeu et al., (2008), la enzima y el sustrato al estar en contacto con la célula se presenta un daño, estrés o de senescencia, dando como resultado la muerte de las células del explante. Existen algunos factores o sustancias que pueden desencadenar el estrés oxidativo y nitrosativo, tales como: intensidad de luz, cortes, herbicidas, senescencia, patógenos, metales pesados, lesiones o sustancias abrasivas (Mittler et al., 2004; Pompeu et al., 2008). Los explantes de especies leñosas presentan esta reacción de oxidación Azofeifa (2009).

En cultivo de tejidos in vitro, la oxidación es causada principalmente por el agente desinfectante durante la asepsia del explante, los cortes, composición del medio de cultivo, volumen y calidad del frasco de cultivo (Tabiyeh et al., 2006; Van Staden et al., 2006; Abdelwahd et al., 2008). El oscurecimiento de explantes o estrés oxidativo se ha relacionado con otros desordenes fisiológicos, morfológicos, epigenéticos y genéticos, que presentan los explantes cultivados, tales como recalcitrancia, hiperhidricidad, variación somaclonal y habituación (Cassells y Curry 2001; Van Staden et al., 2006).

Por lo tanto, podemos señalar que la oxidación en los explantes de $K$. erecta utilizados en este estudio, pudo presentarse por diversos factores, como los antes mencionados; como también por el tiempo de exposición a la temperatura presente en la cámara de flujo.

\section{CONCLUSIONES}

Se presentó del 79 al $83 \%$ de germinación in vitro en semillas de Krameria erecta. Las concentraciones de $0.5,1.0,1.5$ y $2.01 .5 \mathrm{mgL}^{-1}$ de AIB que se utilizaron en las plántulas, presentaron fototropismo negativo, excepto en la concentración cero. Las plántulas in vitro presentaron alturas de 10.07 a $11.65 \mathrm{~cm}$. Al utilizar la concentración de $1.5 \mathrm{mgL}-1$ de AIB presentaron callos y raíz en hoja. Las condiciones asépticas que se manejaron, fueron ideales, al no presentarse contaminación arriba del 15\% en los diferentes 
explantes utilizados. La oxidación se presentó del 26.2 al 30\%, únicamente en yemas axilares y hojas.

\section{AGRADECIMIENTOS}

A las Dras. Claudia Vanessa Baldenegro García y Ana Dolores Armenta Calderón, por sus atenciones y apoyo brindado en la realización de este trabajo de investigación, así como a la Dra. Gloria Irma Ayala Astorga por su apoyo y consejos.

\section{LITERATURA CITADA}

ABDELWAHD R, Hakam N, Labhilili M, Udupa S. 2008. Use of an adsorbent and antioxidants to reduce the effects of leached phenolics in in vitro plantlet regeneration of faba bean. African Journal of Biotechnology. 7:997-1002. ISSN 1684-5315

ARELLANO Y, García E, Vázquez J. 2008. Estimulación de la síntesis de ADN y de proteínas del ciclo celular por auxinas durante la germinación de maíz. Agrociencia. 42(6):637-644. http://www.scielo.org.mx/pdf/agro/v42n6/v42n6a4.pdf

AOSA. Association of Official Seed Analysts. 2005. "Rules fortesting seeds". Association of Official Seed Analysts, USA. [Fecha de consulta: 05 Dic 2019]. https://www.analyzeseeds.com/about-us/

AZCON-BRIETO J, Talon M. (eds). 2008. Fisiología y Bioquímica Vegetal. Editorial McGraw - Hill - Interamericana. 2da Ed. Madrid. ISBN 978-84-481-5168-3

AZOFEIFA Álvaro. 2009. Problemas de oxidación y oscurecimiento de explantes cultivados in vitro. Agronomía Mesoamericana. 20(1): 153-175. ISSN: 1021-7444

CARINI M, G. Aldini G, Orioli M. Facino M. 2002. Antioxidant and photoprotective activity of a lipophilic extract containing neolignans from Krameria triandra roots. Planta Medica. 68: 193-197. http://dx.doi.org/10.1055/s-2002-23167

CASSELLS A, Curry R. 2001. Oxidative stress and physiological, epigenetic and genetic variability in plant tissue culture: implications for micropropagators and genetic engineers. Plant Cell, Tissue and Organ Culture. 64:145-157. http://dx.doi.org/10.1023/A:1010692104861

CÓRDOVA Ana M, Cobos Marianela, Imán SA, Castro Juan C. 2014. Un método eficiente para la inducción de callos in vitro en Myrciaria dubia (Kunth) Mc Vaugh "Camu Camu". $\begin{array}{llll}\text { Scientia } & \text { Agropecuaria. } & \text { 2077-9917. }\end{array}$ http://www.scielo.org.pe/scielo.php?script=sci_arttext\&pid=S207799172014000100003\&lng=es\&tlng=es.

DELGADO MF, Cuba M, Hechenleitner P, Thiers O. 2008. Propagación vegetativa de taique (Desfontainia spinosá) y tepa (Laureliopsis philippiana) con fines ornamentales. Bosque (Valdivia). 29(2):120-126. http://dx.doi.org/10.4067/S0717-92002008000200004 
DOMINGUEZ XA, Rombold C, Verde Star J, Achenbach H, Grob J. 1987. Hermosillol, an 8,3'-Neolignan from Krameria sonorae. Phytochemistry. 26(6):1821-1823. https://doi.org/10.1016/S0031-9422(00)82296-7

FLORES García A, Álvarez Moctezuma JG, Rodríguez de la OJL, Corona Ambris A. 2008. Germinación in vitro de semillas de Nolina parviflora (H.B.K.) Hemsl. Foresta Veracruzana. 10(2):27-33. https://www.redalyc.org/articulo.oa?id=49711436004

GRATÃO PL, Polle A, Lea PJ, Azevedo RA. 2005. Making the life of heavy metal-stressed plants a little easier. Functional Plant Biology. 32(6): 481-494. https://doi.org/10.1071/FP05016

GÓMEZ C, Uribe M, Ríos D, Sánchez-Olate M. 2006. Inducción de callo embriogénico en Eucalyptus globulus Labill. INCI. 31(10). ISSN: 0378-1844

GOLUBOV J, Mandujano MC, Arizaga S, Martínez-Palacios A, Koleff P. 2007. Inventarios y conservación de Agavaceae y Nolinaceae. En: Colunga Garcia Marín P, LarquéSaavedra A, Eguiarte LE, Zizumbo-Villarreal D (Eds.). En lo ancestral hay futuro: del tequila, los mezcales y otros agaves. Centro de Investigación Científica de Yucatán, A.C. Mérida, Yucatán, México. Pp. 133-152. ISBN: 978-968-6532-18-0.

HERNÁNDEZ Yuniet, González María E. 2010. Efectos de la contaminación microbiana y oxidación fenólica en el establecimiento in vitro de frutales perennes. Cultivos tropicales. 31(4). ISSN 0258-5936. http://scielo.sld.cu/scielo.php?script=sci_arttext\&pid=S025859362010000400015

HOWELL SH, Lall S, Che P. 2003. Cytokinins and shoot development. Trends Plant Science. 8:453-459. http://dx.doi.org/10.1016/S1360-1385(03)00191-2

ISTA. International Seed Testing Association. 2019. International Rules for Seed Testing. Zurich, Switzerland: Seed Science \& Technology. ISBN: 3906549275

JIMÉNEZ-ESTRADA M, Velázquez-Contreras C, Garibay-Escobar A, Sierras-Canchola D, Lapizco-Vázquez R, Ortiz-Sandoval C, Burgos-Hernández A, Robles-Zepeda RE. 2013. In vitro antioxidant and antiproliferative activities of plants of the ethnopharmacopeia from northwest of Mexico. BMC Complementary and Alternative Medicine. 13: 329. https://doi.org/10.1186/1472-6882-13-12

LEVITUS G, Echenique V, Rubinstein C, Hopp E, Mroginski L. 2010. Biotecnología y Mejoramiento Vegetal II. Instituto Nacional de Tecnología Agropecuaria, Argentina. https://www.agroindustria.gob.ar/sitio/areas/escuelagro/_archivos/000011_INTA\%20Biot ecnologia/000000_Inta\%20-\%20B\%C3\%ADotecnolog\%C3\%ADa.pdf

LÓPEZ-GÓMEZ P, Iracheta-Donjuan L, Castellanos-Juárez M, Méndez-López I, Sandoval-Esquivez A, Aguirre-Medina JF, Gutiérrez-Díez A. 2010. Influencia del explante 
y medio de cultivo en la embriogénesis somática en hojas de café. Revista fitotecnia mexicana. 33(3):205-213. ISSN: 0187-7380.

MC-CAUGHEY-ESPINOZA D, Reyes-Olivas Á, Ayala-Astorga G, Lugo-García G, OchoaMeza A, Pacheco-Olvera A. 2019. Análisis químico proximal de Krameria erecta del Estado de Sonora. Abanico Veterinario. 9(1):1-12. ISSN 2448-6132. http://dx.doi.org/10.21929/abavet2019.923

MITTLER R, Vanderauwera S, Gollery M, Breusegem F. 2004. Reactive oxygen gene network of plants. Trends in Plant Science. 9:490-498. http://dx.doi.org/10.1590/S010390162008000500015

MORÁN-PALACIO EF, Zamora-Álvarez LA, Stephens-Camacho NA, Yáñez-Farías GA, Virgen-Ortiz A, Martínez-Cruz O, Rosas-Rodríguez JA, 2014. Antioxidant capacity, radical scavenging kinetics and phenolic profile of methanol extracts of wild plants of Southern Sonora, Mexico. Tropical Journal of Pharmaceutical Research. 13: 14871493. http://dx.doi.org/10.4314/tjpr.v13i9.15

ORLIKOWSKA T, Nowak K, Reed B. 2017. Bacteria in the plant tissue culture environment. Plant Cell, Tissue and Organ Culture. 128(3):487-508. https://doi.org/10.1007/s11240-016-1144-9

PEDROZA-MANRIQUE JA, González-Molina SR, Téllez-Ortiz DC. 2007. Micropropagación de Dodonea viscosa (L) Jacq: una especie en vías de extinción. Revista Colombiana de Biotecnología. 9(2):33-44. ISSN 1909-8758.

PÉREZ M, Hernández C, Teresa M, Delgado M. 2009. Expresión transitoria GUS en callos de arroz (var. J-104) mediante la optimización de las condiciones de cultivo in vitro. Rev. Colomb. Biotecnol. 11(2):75-84. ISSN 0123-3475.

POMPEU Georgia G, Vitorello P, Azevedo V. 2008. Antioxidant isoenzyme responses to nickel-induced stress in tobacco cell suspension culture. Sciencia Agricola. 65: 548-552. http://dx.doi.org/10.1590/S0103-90162008000500015.

RODRÍGUEZ Beraud MM, Latsague Vidal MI, Chacón Fuentes MA, Astorga Brevis PK. 2014. Inducción in vitro de callogénesis y organogénesis indirecta a partir de explantes de cotiledón, hipocótilo y hoja en Ugni molinae. Bosque (Valdivia). 35(1):111-118. https://dx.doi.org/10.4067/S0717-92002014000100011

SIMPSON BB, Salywon A. 1999. Families of the vascular Plant of Krameria. Journal of the Arizona-Nevada Academy of Science. 32(1):57. ISSN: 1931-3616.

SIMPSON BB, Weeks A, Helfgott DM, Larkin LL. 2004. Species relationships in Krameria (Krameriaceae) based on ITS sequences and morphology: implications for character utility and biogeography. Systematic Botany. 29: 97-108. https://doi.org/10.1600/036364404772974013 
SMITH PM, Atkins CA. 2002. Purine biosynthesis: Big in cell division, even bigger in nitrogen assimilation. Plant Physiology. 128:793-802. https://doi.org/10.1104/pp.010912

SMITH R. 2012. Plant tissue culture: Techniques and experiments. Londres, UK. Academic Press Elsevier. Pp. 208. ISBN:978-0-12-415920-4

SHIRAM V, V Kumar, M Shitole. 2008. Indirect organogenesis and plant regeneration in Helicteres isora L., an important medicinal plant. In vitro Cellular and Developmental Biology Plant. 44:186. https://doi.org/10.1007/s11627-008-9108-3.

SAS. Statistical Analysis System, [SAS Institute Inc]. 2011. JMP versión 9.0.1. Statistical Discovery. From SAS. USA: Author. A Business Unit of SAS Campus Drive Cary, NC 27513.

TABIYEH D, Bernard F, Shacker H. 2006. Investigation of glutathione, salicylic acid and GA3 effects on browning in pistacia vera shoot tips culture. Acta Horticulturae. 726: 201204. https://doi.org/10.17660/ActaHortic.2006.726.31

TANG W, Newton R. 2004. Increase of polyphenol oxidase and decrease of polyamines correlate with tissue browning in Virginia pine (Pinus virginiana Mill.). Plant Science. 167: 621-628. https://doi.org/10.1016/j.plantsci.2004.05.024

TRIGIANO RN, Gray DJ. 2011. Plant tissue culture, development, and biotechnology. Eds. CRC Press Boca Raton, Florida, USA. Pp. 359-364. ISBN 9781420083262. https://doi.org/10.1201/9781439896143

VAN Staden J, Fennell C, Taylor N. 2006. Plant stress in vitro: the role of phytohormones. Acta Horticulturae. 725:55-62. https://doi.org/10.17660/ActaHortic.2006.725.2

VATANPOUR-AZGHANDI A, Villiers T, Ghorbani A, Tajabadi A. 2002. The microscopy of tissue decolouration and browning problem in pistachio callus cultures. Acta Horticulturae. 591: 377-388. https://doi.org/10.17660/ActaHortic.2002.591.58 